\title{
Cylindrocladium spathiphylli de espatifilo (Spathiphyllum wallisii Rengel): detecção de enzimas extracelulares em isolados normais e alterados por temperatura
}

\author{
Bruna Cristina Migotto ${ }^{1,2}$, Ana Beatriz Monteiro Ferreira ${ }^{1,3}$, César Júnior Bueno ${ }^{1 *}$
}

\begin{abstract}
${ }^{1}$ Instituto Biológico / APTA. Rodovia Heitor Penteado, Km 03, Jardim das Palmeiras, Caixa Postal 70, 13092-543, Campinas-SP-Brasil; ${ }^{2,3}$ Bolsistas do PIBIC/CNPq e FUNDAG.

*Autor para correspondência: César Júnior Bueno (cjbueno@biologico.sp.gov.br).

Data de chegada: 21/11/2012. Aceito para publicação em: 15/03/2013.
\end{abstract}

1861

\section{RESUMO}

Migotto, B.C.; Ferreira, A.B.M.; Bueno, C.J. Cylindrocladium spathiphylli de espatifilo (Spathiphyllum wallisii Rengel): detecção de enzimas extracelulares em isolados normais e alterados por temperatura. Summa Phytopathologica, v.39, n.2, p.89-96, 2013.

O fungo Cylindrocladium spathiphylli causa podridão no colo e nas raízes de espatifilo, induzindo amarelecimento e murcha nas folhas da parte aérea. Há poucos estudos com o fungo quanto às enzimas extracelulares. Assim, delineou-se ensaio inteiramente casualizado in vitro, com três tratamentos (dois isolados normais: LFEEI016 EPAGRI/SC e MMBF 01/01 - IB/SP; mais testemunha) e seis repetições, visando a detecção de enzimas. A amilase (AM), lipase (LP), carboximetilcelulase (CMC) e lacase (LC) foram mensuradas pelo cálculo da área da coroa circular, local de atividade das enzimas. A catalase (CT) e gelatinase (GL) foram mensuradas por símbolos, depois transformados em notas ( 1 a 4, de ausência à intensa produção). $\mathrm{O}$ isolado MMBF 01/01 produziu as maiores áreas e com mais intensidade as enzimas. Das enzimas, a maior área foi a da LC e depois a LP. LFEEI016 e MMBF 01/01 não apresentaram área para $\mathrm{AM}$ e $\mathrm{CMC}$ e exibiram intensidade fraca e igual para CT. A intensidade de GT foi moderada no MMBF 01/01 (nota média 3,0) e ausente para o LFEEI016 (nota média 1,0 ). Após a produção das enzimas extracelulares, os isolados foram alterados vegetativamente por temperatura. Instalou-se ensaio inteiramente ao acaso, em fatorial contendo disco de micélio dos isolados do fungo versus três temperaturas $\left[23^{\circ} \mathrm{C}(\mathrm{T} 1) ; 33^{\circ} \mathrm{C}(\mathrm{T} 2)\right.$ e de $33^{\circ} \mathrm{C}$ para $23^{\circ} \mathrm{C}$ (T3)] versus quatro períodos (3; 6; 9 e 12 dias), com oito repetições, em placa de Petri com BDA mantida em BOD. O diâmetro das colônias foi medido diariamente $(\mathrm{mm})$ em dois sentidos. As alterações de temperatura vistas foram: inócuo, fungistático (FS) e fungicida (FC). Aplicou-se estatística nas temperaturas T1 e T3 dos isolados para checar efeito FS e escolher aqueles com maior e menor efeito. $\mathrm{O}$ isolado LFEEIO16 mostrou efeito FS com três dias às temperaturas $33^{\circ} \mathrm{C}$ e de $33^{\circ} \mathrm{C}$ para $23^{\circ} \mathrm{C}$. Nos demais períodos, o isolado sofreu efeito FC. O MMBF 01/01 mostrou efeito FS em todos os períodos. Ambos isolados sofreram, estatisticamente, efeito FS. O MMBF 01/01 mostrou maior efeito FS aos nove dias, nas temperaturas referidas e menor com três dias. Após a constatação de alteração na taxa de crescimento micelial dos isolados, procurou-se verificar, novamente, a produção de enzimas extracelulares. Os isolados alterados e utilizados foram o MMBF 01/ 01 com três e nove dias e o LFEEIO16 com três dias. A produção e a avaliação das enzimas foram realizadas da mesma maneira para os isolados normais. O isolado MMBF $01 / 01$ - três dias produziu as maiores áreas e com mais intensidade as enzimas. Das enzimas, a maior área foi a da LC. Após LC, a área da LP foi maior que a da CMC nos isolados. Não se detectou área de $\mathrm{AM}$ nos isolados. A intensidade de GL foi maior que a da CT nos isolados MMBF 01/01 com três e nove dias. Para LFEEI016 - três dias, a intensidade média de CT foi nota 2,0 e ausência de GL (nota média 1,3). Sugere-se investigar a severidade da doença na planta entre os isolados e em condições naturais investigar a evolução da LC em comparação as demais enzimas na patogênese do fungo na cultura.

Palavras-chave adicionais: Lacase, caracterização, lírio da Paz, podridão de raiz e colo.

\section{ABSTRACT}

Migotto, B.C.; Ferreira, A.B.M.; Bueno, C.J. Cylindrocladium spathiphylli from spathe flower (Spathiphyllum wallisii Rengel): detection of extracellular enzymes in normal and temperature-changed isolates. Summa Phytopathologica, v.39, n.2, p.89-96, 2013.

The fungus Cylindrocladium spathiphylli causes collar and root rot in spathe flowers, inducing yellowing and wilting of leaves in the shoot. This fungus has been scarcely studied for extracellular enzymes. Therefore, an in vitro assay was carried out in randomized design, with three treatments (two normal isolates: LFEE1016 - EPAGRI and MMBF 01/01 - IB/SP; plus control) and six replicates, for enzyme detection. Amylase (AM), lipase (LP), carboxymethylcellulase (CMC) and laccase (LC) were measured by calculating the annulus area, the activity site of the enzymes. Catalase (CT) and gelatinase (GL) were measured by symbols subsequently transformed into scores (1 to 4 , from absence to intense production). MMBF 01/01 isolate had the largest areas and enzymes with the highest intensity. Of the enzymes, the largest area was that of LC, followed by LP. LFEEI016 and MMBF 01/01 showed no area for AM and CMC and exhibited weak and equal intensity for CT. The intensity of GT was moderate for MMBF 01/ 01 (mean score 3.0) and absent for LFEEI016 (mean score 1.0). After production of extracellular enzymes, the isolates were vegetatively altered by temperatures. The assay was in completely randomized factorial design including mycelial discs of the fungal isolates versus three temperatures $\left[23^{\circ} \mathrm{C}(\mathrm{T} 1), 33^{\circ} \mathrm{C}(\mathrm{T} 2)\right.$ and $33^{\circ} \mathrm{C}$ to $23^{\circ} \mathrm{C}$ (T3)] versus four periods (3, 6, 9 and 12 days) and eight replicates in a Petri dish containing PDA and maintained in a BOD chamber. The diameter of colonies was daily measured $(\mathrm{mm})$ in both directions. The noted changes were: innocuous, fungistatic (FS) and fungicide 
(FC) effect. Statistics was used for temperatures T1 and T3 to verify FS effect and choose the isolates that had higher and lower effect. LFEEI016 isolate showed FS effect at three days at temperatures $33^{\circ} \mathrm{C}$ and from $33^{\circ} \mathrm{C}$ to $23^{\circ} \mathrm{C}$. In the remaining periods, this isolate suffered FC effect. MMBF 01/01 showed FS effect in all periods. Both isolates statistically showed FS effect. MMBF 01/01 showed higher FS effect at nine days, at the mentioned temperatures, and lower effect at three days. After detection of the change in the mycelial growth rate of the isolates, the production of extracellular enzymes was again verified. The changed isolates were MMBF 01/01 at three and nine days and LFEEI016 at three days. Enzyme production and evaluation were carried out as for normal isolates. MMBF 01/01 isolate - three days, produced the largest areas and enzymes with the highest intensity. Of the enzymes, the largest area was that of LC. Following LC, the area of LP was larger than that of CMC in the isolates. The area of AM was not detected in the isolates. The intensity of GL was higher than that of CT in MMBF 01/01 isolates at three and nine days. For LFEEI016 - three days, the mean intensity of CT was score 2.0 and absence of GL (mean score 1.3). The disease severity should be investigated in the plant among isolates, as well as under natural conditions to determine the evolution of LC compared to the remaining enzymes in the pathogenesis of this fungus in the culture.

Additional keywords: Laccase, characterization, spathe flower, collar and root rot.

Spathiphyllum wallisii Rengel é uma planta ornamental muito popular, nativa da América do Sul e cultivada sob sistemas intensivos em casas-de-vegetação e comercializada, principalmente, em vasos. Pertence à família Araceae e é conhecida como espatifilo, bandeira branca ou lírio da paz $(32,37)$.

O principal fitopatógeno do espatifilo é Cylindrocladium sphathiphylli Schoulties, El-Gholl \& Alfieri (teleomorfo: Calonectria spathiphylli El-Gholl, Uschida, Alfenas, Schub \& Alfieri), um fungo habitante de solo. Ele causa, na planta, podridão no colo e nas raízes, com sintomas reflexos na parte aérea na forma de amarelecimento foliar e murcha. Com a evolução da doença, ocorre a morte da planta $(14,22,37)$. A incidência do patógeno na cultura é comum em todos os países onde se cultiva o espatifilo $(10,41)$.

Pascholati (33) relata "que para um fitopatógeno infectar uma planta (patogênese) é preciso que o mesmo consiga penetrar e colonizar os tecidos do seu hospedeiro, retirar os nutrientes necessários para sua atividade e sobrevivência, bem como neutralizar as reações de defesa da planta. Para isso, o patógeno utiliza-se de substâncias tais como enzimas, toxinas e hormônios".

Segundo Bateman \& Basham (6), muitos fungos produzem enzimas extracelulares de importância na degradação e transporte de nutrientes para a célula e no processo de patogênese. Oliveira Silva et al. (31) relatam que as enzimas extracelulares poderão ser um indicativo da característica patogênica dos fungos.

As enzimas são grandes moléculas de proteína que catalisam todas as reações inter-relacionadas em uma célula viva. Elas aceleram as reações bioquímicas a uma determinada temperatura que seja compatível com o funcionamento normal da célula. A especificidade das enzimas é possibilitada por suas estruturas; a configuração única que possui cada enzima permite a ligação com o substrato correto entre as diversas moléculas que existem nas células. Portanto, para cada tipo de reação química que ocorre em uma célula, há uma determinada enzima que catalisa essa reação $(1,42)$.

Krugner \& Bacchi (25) e Kuniega-Alonso et al. (26) reportam que o crescimento micelial ou vegetativo é uma característica importante para a grande maioria dos fungos, sobretudo para os fitopatogênicos, pois o micélio coloniza o seu substrato, absorvendo água e nutrientes. A estrutura vegetativa sofre modificações na sua morfologia, formando estruturas especializadas ou agrega-se formando, também, diferentes tipos de estruturas, com diferentes funções, a exemplo das estruturas de resistência no solo. Além de atuar também como uma estrutura de sobrevivência em restos vegetais, o micélio libera enzimas que decompõe substâncias complexas presentes no substrato, tornado assim assimiláveis.
Gowariker et al. (20) e Basseto et al. (4) comentam que o efeito fungistático inibe, temporariamente, o crescimento micelial do fungo; isto pode ter como causa uma substância ou composto ou, ainda, outros fatores. Segundo, ainda, Basseto et al. (4), o fungo que sofreu efeito fungistático pode apresentar alteração, na sua fisiologia vegetativa (micélio). Assim, a fungistase, além de alterar o micélio, pode alterar as enzimas extracelulares e essas enzimas alteradas, por sua vez, podem influenciar o processo de colonização do substrato, no caso até da patogênese nas plantas.

O objetivo específico do trabalho foi detectar in vitro algumas enzimas extracelulares produzidas por isolados normais e alterados por temperatura (fungistase) de Cylindrocladium spathiphylli de espatifilo, visando no futuro averiguar qual (is) enzima (s) pode (m) estar correlacionada (s) com a patogênese.

\section{MATERIAL E MÉTODOS}

Todos os ensaios foram realizados nas dependências do Laboratório de Fitopatologia do Centro Experimental Central do Instituto Biológico / APTA.

Dois isolados patogênicos de C. spathiphylli foram obtidos, sendo um da micoteca da EPAGRI de Itajaí/Santa Catarina (LFEEI016) e outro do Centro de Sanidade Vegetal do Instituto Biológico de São Paulo (MMBF 01/01). Aparecido et al. (2) testaram e constataram a patogenicidade do isolado MMBF 01/01 em mudas de espatifilo. Quanto ao isolado LFEEI016, Visconti et al. (45) testaram e constataram a patogenicidade dele em mudas de espatifilo no cultivar Opal.

O inóculo de cada isolado normal do fungo foi produzido em placas de Petri de vidro, de $90 \mathrm{~mm}$ de diâmetro, contendo meio de batata-dextrose-ágar (BDA), que foram mantidas em estufa tipo BOD, a $23^{\circ} \mathrm{C}$, na ausência de luz, por oito dias. Após o preparo dos meios específicos para a detecção das enzimas, um disco de meio BDA contendo cada isolado do fungo foi transferido para o centro de cada placa ou para tubo de ensaio contendo os meios específicos das enzimas.

A amilase foi detectada em meio $\left(6 \mathrm{~g}\right.$ de $\mathrm{NaNO}_{3} ; 1,5 \mathrm{~g}$ de $\mathrm{KH}_{2} \mathrm{PO}_{4}$; $0,5 \mathrm{~g}$ de $\mathrm{KCl} ; 0,5 \mathrm{~g}$ de $\mathrm{MgSO}_{4} \cdot 7 \mathrm{H}_{2} \mathrm{O} ; 0,01 \mathrm{~g}$ de $\mathrm{FeSO}_{4} ; 0,01 \mathrm{~g}$ de $\mathrm{ZnSO}_{4} ; 15 \mathrm{~g}$ de ágar; $1 \mathrm{~L}$ de água destilada) contendo $1 \%$ de amido solúvel, em pH 6,8. Adicionaram-se $5 \mathrm{~mL}$ de solução de lugol, por 10 minutos, em cada placa, após manter as mesmas em BOD, a $23^{\circ} \mathrm{C}$, por 5 dias, no escuro, para verificar a atividade amilolítica. Resultado positivo refere-se a um halo amarelado ao redor da colônia em contraste com um fundo roxo (34). 
A carboximetilcelulase foi verificada em meio específico $(0,5 \mathrm{~g}$ $\mathrm{NaNO}_{3} ; 1,0 \mathrm{~g} \mathrm{~K}_{2} \mathrm{HPO}_{4} ; 0,5 \mathrm{~g} \mathrm{MgSO}_{4} .7 \mathrm{H}_{2} \mathrm{O} ; 0,001 \mathrm{~g} \mathrm{FeSO}_{4} .7 \mathrm{H}_{2} \mathrm{O} ; 1,0$ $\mathrm{g}$ de Extrato de Levedura; $16 \mathrm{~g}$ Agar e $1000 \mathrm{~mL}$ de $\mathrm{H}_{2} \mathrm{O}$ ), suplementado com $1 \%$ de carboximetil-celulose. A atividade desta enzima, após incubação do meio em BOD, a $23^{\circ} \mathrm{C}$, por 5 dias, no escuro, foi verificada pela presença de zonas claras, ao redor da colônia dos isolados, após a aplicação de $5 \mathrm{~mL}$ de solução de lugol, colocada sob a superfície das mesmas, por um período de 5 minutos, seguido de lavagem com solução salina (23).

A lipase foi constatada em meio de Sierra (1957) citado por Bastos (5), contendo Tween 20 e $0,001 \%$ de Rodamina B, com pH ajustado para 6,0 . Após manter as placas em $\mathrm{BOD}$, a $23^{\circ} \mathrm{C}$, por 5 dias, no escuro, as mesmas foram resfriadas a $4^{\circ} \mathrm{C}$, por 96 horas. A atividade lipolítica foi observada como um precipitado visível, devido à formação de cristais de cálcio ou como um halo claro deste precipitado, ao redor das colônias. Os Tweens são gorduras sintéticas com uma cadeia de sorbitol (um álcool de açúcar com cinco carbonos em vez de glicerol, o qual tem três carbonos) esterificados em vários ácidos graxos. A enzima lipase hidrolisa a ligação éster entre o carbono do sorbitol e o carbono carbonil do ácido graxo para formar sorbitol e um ácido graxo livre. Alterações em $\mathrm{pH}$ e ligação de cálcio com ácidos graxos livres se combinam para produzir o precipitado branco e floculento suspenso no meio, os cristais de cálcio (43).

A atividade de fenol-oxidases (lacase) foi vista em meio contendo $20 \mathrm{~g}$ de ágar acrescido de $0,5 \%(\mathrm{p} / \mathrm{v})$ de ácido gálico, $15 \mathrm{~g}$ extrato de malte e $1 \mathrm{~g}$ de peptona em 1 Litro de água destilada. $\mathrm{O}$ ácido gálico foi homogeneizado em $50 \mathrm{~mL}$ de água destilada e autoclavado a $120^{\circ} \mathrm{C}, 1 \mathrm{~atm}$, por 10 minutos. Os demais reagentes foram solubilizados $\left(\mathrm{pH} \mathrm{7,0)}\right.$ e autoclavados $\left(120^{\circ} \mathrm{C}, 1 \mathrm{~atm}, 20\right.$ minutos). O teste foi considerado positivo para aquelas colônias que formaram ao seu redor um halo marrom escuro (reação de Bavendamm) (13), após as placas serem mantidas em BOD, a $23^{\circ} \mathrm{C}$, por 5 dias, no escuro. Segundo Trigiano et al. (43), "a polifenol oxidases oxida grupos hidroxila adjacentes em ácido gálico e cria quinonas, as quais são instáveis e espontaneamente são polimerizadas para formarem produtos pigmentados".

A atividade da catalase foi constatada em meio BDA, com adição posterior de solução de peróxido de hidrogênio a 3\% (3 gotas com tempo de reação de 5 minutos), sobre a cultura fúngica, segundo metodologia modificada de Shin \& Kim (39), após as placas serem mantidas em BOD, a $23^{\circ} \mathrm{C}$, por 5 dias, no escuro. Resultado positivo foi considerado quando houve formação de bolhas ao redor ou na colônia do isolado do fungo.

A atividade proteolítica (ou proteases) foi constatada através da verificação da produção da enzima gelatinase. A gelatinase foi verificada em tubos de ensaio contendo o meio composto de $3,0 \mathrm{~g}$ extrato de carne, 5,0 g de peptona e $120 \mathrm{~g}$ de gelatina, em 1 Litro de água destilada. Após cinco dias de incubação em $\mathrm{BOD}$, a $23^{\circ} \mathrm{C}$, no escuro, os tubos foram colocados em temperatura de geladeira $\left(4^{\circ} \mathrm{C}\right)$ por uma hora. Considerou-se como resultado positivo, quando os tubos de cultivo, sob refrigeração, não voltaram ao estado sólido (44).

Todos os meios foram autoclavados a $120^{\circ} \mathrm{C}, 1 \mathrm{~atm}$, por 20 minutos, com exceção de alguns substratos como o ácido gálico e o Tween 20, que foram autoclavados à parte, a $120^{\circ} \mathrm{C}, 1 \mathrm{~atm}$, por 10 minutos; após serem resfriados, foram acrescentados ao meio original.

$\mathrm{O}$ delineamento experimental adotado foi o inteiramente ao acaso, em esquema de dois fatores (isolados versus enzimas), com seis repetições, sendo a parcela (repetição) representada por uma placa de Petri de plástico descartável ( $90 \mathrm{~mm}$ de diâmetro) ou tubo de ensaio de vidro, contendo o meio mais um isolado do fungo. $\mathrm{O}$ tratamento controle dos testes (testemunha) constituiu-se de meios contendo discos de meio de cultura (BDA), sem que estivessem colonizados pelos isolados do fungo.

A avaliação das enzimas amilase, carboximetilcelulase, lipase e lacase (oxidase) consistiram na medição de dois diâmetros ortogonais da colônia e da colônia mais o halo. A atividade das enzimas citadas foi estimada, semiquantitativamente, calculando-se a área da coroa circular (19), que é o local de atividade. O diâmetro do halo foi transformado em raio e este colocado na fórmula da coroa circular. Seguindo Bastos (5), uma estimativa subjetiva da produção das enzimas gelatinase (protease) e catalase foi mensurada por meio de símbolos, baseandose, respectivamente, na intensidade da liquefação do meio ou na formação de bolhas: +++ (intensa); ++ (moderada); + (fraca) e (ausência).

Os dados das áreas $\left(\mathrm{mm}^{2}\right)$ das enzimas amilase, carboximetilcelulase, lipase e lacase (oxidase) por tratamento e por enzimas foram submetidos à análise não-paramétrica de Kruskal-Wallis, complementada com o teste $\mathrm{T}$ de diferença de médias ao nível de $1 \%$ de probabilidade.

Visando-se a analisar estatisticamente os dados das enzimas gelatinase e catalase por tratamento (dois isolados mais testemunha), os símbolos foram substituídos pelas notas a seguir: $+++=4,0 ;++=$ 3,$0 ;+=2,0 \mathrm{e}-=1,0$. Após isso, efetuou-se a análise não-paramétrica de Kruskal-Wallis, complementada com o teste $\mathrm{T}$ de diferença de médias ao nível de $1 \%$ de probabilidade. A análise das diferenças das intensidades das enzimas catalase e gelatinase por isolado e testemunha foi feita por meio da análise não-paramétrica de Mann-Whitney, complementada pelo teste de Wilcoxon ao nível de $1 \%$ de probabilidade.

Para o ensaio de alteração micelial, o inóculo de cada isolado do fungo foi produzido em placas de Petri de plástico estéril, de 90 $\mathrm{mm}$ de diâmetro, contendo meio BDA, mantidas em estufa tipo $\mathrm{BOD}$, a $23^{\circ} \mathrm{C}$, com fotoperíodo de 12 horas de luz, por oito dias. $\mathrm{O}$ delineamento do ensaio foi inteiramente ao acaso, em esquema fatorial, com os dois isolados versus três temperaturas $\left[23^{\circ} \mathrm{C}(\mathrm{T} 1)\right.$; $33^{\circ} \mathrm{C}(\mathrm{T} 2)$ e de $33^{\circ} \mathrm{C}$ para $\left.23^{\circ} \mathrm{C}(\mathrm{T} 3)\right]$ versus quatro períodos $(3 ; 6$; 9 e 12 dias), com oito repetições. A parcela (repetição) foi representada por uma placa de Petri de plástico, com meio BDA, mais um disco $(0,5 \mathrm{~cm}$ de diâmetro $)$ de meio colonizado pelo isolado do fungo colocado no centro da placa. $\mathrm{O}$ diâmetro das colônias dos isolados foi medido diariamente em dois sentidos, horizontal e vertical, em milímetros, com auxílio de uma régua milimetrada. Após as medições, o efeito das temperaturas foi averiguado pelos seguintes parâmetros: 1) inócuo, a taxa de crescimento diário do micélio das colônias permaneceu igual em todas as temperaturas; fungistático, a taxa de crescimento diário da T3 menor que a da T1; 3) fungicida, as taxas de crescimento das temperaturas $T 2$ e $T 3$ iguais e muito inferiores que a taxa da T1.

Constatado efeito fungistático, calculou-se a taxa de crescimento médio do micélio das temperaturas T1 e T3 dos isolados. Essas taxas foram comparadas estatisticamente, tanto por períodos (análise não-paramétrica de Krukal-Wallis, complementada pelo teste $\mathrm{T}$ ao nível de $5 \%$ de probabilidade), quanto por isolados (análise não-paramétrica de Mann-Whitney ao nível de 5\% de probabilidade).

Após a obtenção de isolados alterados por temperatura, realizouse novo ensaio visando a detectar a produção de enzimas extracelulares. Assim, a produção de inóculo, a confecção dos meios específicos, a montagem do ensaio, a avaliação e a análise dos dados foram idênticas ao ensaio com os isolados normais. 


\section{RESULTADOS E DISCUSSÃO}

Na média geral das enzimas amilase, carboximetilcelulase, lipase e lacase, constatou-se que o isolado MMBF 01/01 foi, significativamente, o que produziu a maior área destas em comparação ao isolado LFEEI016 e testemunha. Dentre as enzimas, independentemente do isolado, a maior área foi a da lacase, seguida da lipase e estatisticamente semelhante vem carboximeticelulase e amilase, sendo que para ambas não se visualizou nenhuma área para nenhum isolado (Tabela 1).

Na média geral das enzimas catalase e gelatinase, observaram-se, novamente, diferenças entre os isolados e esses em relação à testemunha. O isolado MMBF 01/01 foi, novamente, o que apresentou maior intensidade destas enzimas. $\mathrm{Na}$ média geral dos tratamentos, não se constatou diferença entre essas enzimas quanto à intensidade (Tabela 1).

Cuzzi et al. (15) avaliaram a capacidade de produção das enzimas extracelulares lipase, amilase e protease de 11 espécies de fungos endofíticos, incluindo Cylindrocladium sp. e isolados de Baccharis dracunculifolia D.C. O isolado de Cylindrocladium sp. produziu, segundo o critério adotado pelo autores, fortemente a enzima lipase, de maneira positiva a amilase e negativa para protease. Os dois isolados de C. spathiphylli do presente trabalho também apresentaram áreas da enzima lipase, sendo que essa enzima apresentou a segunda maior área em comparação com a área da enzima lacase (Tabela 1). Segundo Kolattukudy (24), há evidências de que a cutinase, uma lipase capaz de degradar a cutina, esteja correlacionada à penetração de fungos pela cutícula das plantas, desempenhando assim um importante papel na patogenicidade. As lipases e as estereases são enzimas associadas ao metabolismo e à hidrólise de lipídeos. Portanto, as lipases hidrolisam parcial ou totalmente o triaciglicerol, a diacilglicerol, o monoacilglicerol, o glicerol e os ácidos graxos, agindo na interface óleo/água $(9,35)$. Dentre os gêneros de fungos filamentosos descritos como produtores de lipase estão Aspergillus, Fusarium, Geotrichum, Mucor, Penicillium, Rhizomucor, Rhizopus e Thermomyces (30). Além do trabalho de Cuzzi et al. (15), o fungo C. spathiphylli, de espatifilo, segundo dados da Tabela 1, poderá ser acrescido na lista de Oliveira (30) no gênero de fungos produtores de lipase também.

De acordo com Dianese (16), é muito comum as amilases serem produzidas pelos fungos, as quais hidrolisam o amido. No entanto, desconhece-se a importância desta enzima na patogênese. Segundo Griffin (21), fungos podem utilizar o amido como fonte de energia para o seu crescimento e esporulação. A produção desta enzima é variável entre os gêneros e dentro das espécies dos fungos (29). No presente trabalho (Tabela 1), com a metodologia utilizada, observouse que os dois isolados de C. spathiphylli não formaram nenhuma área para a enzima amilase.

Os fungos decompositores de substâncias celulósicas estão principalmente no solo, colonizando os vegetais, suas raízes e os seus resíduos. As celulases hidrolisam a celulose, resultando na produção final de glicose (38). A glicose é fonte de energia para os fungos. Assim, Ruegger \& Tauk-Tornisielo (38) investigaram a produção de celulase por fungos isolados do solo da Estação Ecológica de JuréiaItatins, São Paulo, Brasil. Dentre os fungos isolados havia Cylindrocladium clavatum e esse produziu 1,6 de índice enzimático quanto à produção da enzima extracelular carboximetilcelulase. Apesar dos comentários e do trabalho de Ruegger \& Tauk-Tornisielo (38), os dois isolados do fungo de solo $C$. spathiphylli não formaram nenhuma área para a enzima carboximetilcelulase (Tabela 1). Segundo ainda Ruegger \& Tauk-Tornisielo (38), a produção de celulases depende do tipo de substrato utilizado e que o uso de distintos métodos torna difícil a comparação com os resultados obtidos por autores diferentes. Esse fato ocorreu entre os dados do presente trabalho com os de Ruegger \& Tauk-Tornisielo (38), ou seja, a metodologia utilizada para produção de carboximetilcelulase pelos isolados de C. spathiphylli foi diferente da testada por Ruegger \& Tauk-Tornisielo (38) para o fungo C. clavatum.

Os dois isolados de C. spathiphylli (Tabela 1) apresentaram intensidade fraca e igual para a enzima catalase. Há descrição de que a catalase e o ácido ascórbico são potentes antioxidantes, que quando introduzidos em células de soja (Glycine max) são capazes de bloquear o acúmulo da fitoalexina gliceolina, induzida por Verticillium dahliae, sugerindo que a produção de catalase, pelo lado do patógeno, provavelmente seja capaz de suprimir as respostas de defesa da planta (17).

Os dois isolados de C. spathiphylli (Tabela 1) apresentaram intensidade diferentes para a enzima gelatinase (protease), sendo moderada para o isolado MMBF 01/01 e ausência para LFEEI016. Sing \& Saxena (40) descreveram tanto in vitro quanto in vivo, a produção de proteases pelo fungo Fusarium solani de couve-flor (Brassica oleracea var. botrytis). Os autores associaram o papel das proteases e de outras enzimas com a murcha causada pelo fungo na cultura.

Ambos os isolados de C. spathiphylli apresentaram área para a enzima lacase, mas essa área foi maior no isolado MMBF 01/01 que no isolado LFEEI016. A área desta enzima foi maior dentre a área das demais enzimas (Tabela 1). A podridão de raízes de seringueira, causada

Tabela 1. Enzimas extracelulares detectadas em isolados normais de Cylindrocladium spathiphylli, em meios de cultura específicos mantidos em condições de incubação em estufa tipo BOD.

\begin{tabular}{|c|c|c|c|c|c|c|c|c|}
\hline \multirow{2}{*}{$\begin{array}{l}\text { Enzimas extracelulares/ } \\
\text { Tratamentos (Isolados) }\end{array}$} & Amilase & Carboximetil-celulase & Lipase & Lacase & Média & Catalase & Gelatinase & Média \\
\hline & \multicolumn{5}{|c|}{ Área das enzimas $\left(\mathrm{mm}^{2}\right)$} & \multicolumn{3}{|c|}{ Escala de notas quanto à intensidade } \\
\hline LFEEI016 & $0,00^{1} \mathrm{a}^{2} \mathrm{C}^{3}$ & 0,00 a $\mathrm{C}$ & 578,05 b B & $747,23 \mathrm{~b} \mathrm{~A}$ & $331,32 \mathrm{~b}$ & $2,0^{4} a^{5} A^{6}$ & $1,0 \mathrm{~b} \mathrm{~B}$ & $1,5 \mathrm{~b}$ \\
\hline Testemunha & 0,00 & 0,00 a $\mathrm{A}$ & $0,00 \mathrm{c} \mathrm{A}$ & $0,00 \mathrm{c} \mathrm{A}$ & $0,00 \mathrm{c}$ & b A & $1,0 \mathrm{~b} \mathrm{~A}$ & $1,0 \mathrm{c}$ \\
\hline Média & 0,00 & 0,00 & 437,49 & 858,02 & & 1,7 & 1,7 & \\
\hline
\end{tabular}

${ }^{1}$ Média de seis repetições; ${ }^{2}$ Letras minúsculas iguais, na coluna, para as enzimas amilase, carboximetilcelulase, lipase e lacase não diferem entre si ao nível de $1 \%$ de probabilidade, segundo teste T da análise não-paramétrica de Kruskal-Wallis; ${ }^{3}$ Letras maiúsculas iguais, na linha, para as enzimas amilase, carboximetilcelulase, lipase e lacase não diferem entre si ao nível de $1 \%$ de probabilidade, segundo teste $\mathrm{T}$ da análise não-paramétrica de Kruskal-Wallis; ${ }^{4}$ Média de seis repetições. Escala de notas, sendo $1=$ ausência (ou $-=$ símbolo: ausência); $2=$ fraca (ou + =símbolo: fraca); $3=$ moderada ( ou $++=$ símbolo: moderada); 4=intensa (ou $+++=$ símbolo: intensa), sendo que para catalase refere-se ao tamanho da formação das bolhas e para a gelatinase quanto à liquefação ou não do meio; ${ }^{5}$ Letras minúsculas iguais, na coluna, para as enzimas catalase e gelatinase não diferem entre si ao nível de $1 \%$ de probabilidade, segundo teste $\mathrm{T}$ da análise não-paramétrica de Kruskal-Wallis; ${ }^{6}$ Letras maiúsculas iguais, na linha, para as enzimas catalase e gelatinase não diferem entre si ao nível de $1 \%$ de probabilidade, segundo teste de Wilcoxon da análise não-paramétrica de Mann-Whitney. 
tanto por Rigidoporus lignosus quanto por Phellinus noxius, e os seus aspectos fisiológicos e bioquímicos nos tecidos infectados foram investigados por Geiger et al. (18). Os fungos citados pelos autores produzem, in vitro, as enzimas celulase, pectinase e lacase. Segundo os autores, a enzima lacase é produzida em maior quantidade por $R$. lignosus do que por P. noxius, quando se investiga filtrado de cultura e tecido parasitado. Ainda segundo Geiger et al. (18), a lacase é excretada apenas pelos fungos e não pela planta hospedeira, pois essa enzima presente no tecido parasitado é homologa àquela produzida pelos fungos em condições in vitro. Segundo os autores, as enzimas excretadas pelos fungos são, efetivamente, capazes de degradar polímeros de tecidos lignificados in vitro.

As lacases são produzidas por fungos, plantas superiores (36) e, também, por bactérias (11). Em fungos, elas estão envolvidas em degradação de lignina (8), produção de pigmento (12) e, também, na patogênese de plantas (18).

De acordo com os dados da Tabela 2, o isolado LFEEIO16 apresentou efeito fungistático sobre o crescimento micelial com três dias de exposição às temperaturas $33^{\circ} \mathrm{C}$ e de $33^{\circ} \mathrm{C}$ para $23^{\circ} \mathrm{C}$. Nos demais períodos, o isolado sofreu efeito fungicida sobre seu micélio. O isolado MMBF 01/01 apresentou efeito fungistático sobre o micélio, em todos os períodos testados (Tabela 2).

Basseto et al. (4) também verificaram efeito fungistático e fungicida sobre o micélio de Fusarium oxysporum f. sp. lycopersici raça 2, Rhizoctonia solani AG-4 HGI e Sclerotium rolfsii, quando incubados em temperatura de $37^{\circ} \mathrm{C}$ e depois retorno a $25^{\circ} \mathrm{C}$.

De acordo com os dados da Tabela 3, tanto o isolado da Epagri, quanto o isolado do Instituto Biológico, apresentaram, realmente, efeito fungistático, pois, após o tratamento a $33^{\circ} \mathrm{C}$ e recolocação das placas em temperatura de $23^{\circ} \mathrm{C}$, o micélio deles reduziu, significativamente, a taxa de crescimento, quando comparado à taxa dos isolados colocados, somente, à temperatura de $23^{\circ} \mathrm{C}$.

$\mathrm{O}$ isolado MMBF 01/01 apresentou maior redução significativa na taxa de crescimento do micélio pela fungistase, no período de nove dias, às temperaturas $23^{\circ} \mathrm{C}$ e de $33^{\circ} \mathrm{C}$ para $23^{\circ} \mathrm{C}(1,8 \mathrm{~mm})$ e menor com três dias $(0,9 \mathrm{~mm})$ (Tabela 3$)$.

Segundo Basseto et al. (3), os fungos que apresentaram efeito fungistático apresentaram, também, significativa redução na taxa de crescimento dos seus micélios.

Basseto et al. (4) e Gowariker et al. (20) comentam que o efeito fungistático consiste na paralisação momentânea do crescimento micelial dos fungos, quando incubados à temperatura de $37 \pm 2^{\circ} \mathrm{C}$, nos diferentes períodos testados, voltando a crescer, apenas, quando incubados a $25 \pm 2{ }^{\circ} \mathrm{C}$. Eles ressaltam, entretanto, para o efeito fungistático, que apesar dos fungos voltarem a se desenvolver, quando incubados a $25 \pm 2^{\circ} \mathrm{C}$, os mesmos apresentam uma taxa média de crescimento micelial significativamente inferior à observada para seu respectivo controle geral $\left(25^{\circ} \mathrm{C}\right)$, indicando uma alteração na fisiologia vegetativa destes fitopatógenos.

Portanto, os dados dos isolados de C. spathiphylli apresentaram comportamento semelhantes aos observados por Basseto et al. (4). Além do trabalho de Basseto et al. (4), Mishra \& Pandey (28) comentam que solo aquecido, acima de $80^{\circ} \mathrm{C}$, perde completamente a fungistase. Nenhuma fungistase é recuperada em amostras de solo, quando são vaporizadas em autoclave, por 15 minutos.

Há outros fatores que podem causar fungistase, além da temperatura. Bautista-Baños et al. (7) estudaram os efeitos de quitosana e extratos de plantas no crescimento de Colletotrichum gloeosporioides, no nível de antracnose e na qualidade dos frutos de mamão. Quitosana a 2 e $3 \%$ causaram efeito fungicida sobre o fungo. Extratos de plantas

Tabela 2. Efeitos de fungistase, fungicida ou inócuo provocados pela temperatura de $33^{\circ} \mathrm{C}$ e depois retorno a temperatura de $23^{\circ} \mathrm{C}$ sobre $\mathrm{o}$ micélio de isolados de Cylindrocladium spathiphylli, de espatifilo, incubados em condições de BOD, em diferentes períodos.

\begin{tabular}{|c|c|c|c|c|c|c|c|c|c|c|c|c|}
\hline \multirow{2}{*}{ ISOLADOS } & \multicolumn{12}{|c|}{ PERÍODOS (DIAS) } \\
\hline & $\mathbf{I N}^{2}$ & \multicolumn{11}{|c|}{ EFEITOS DATEMPERATURA } \\
\hline LFEEI016 & $-^{1}$ & + & - & - & - & + & - & - & + & - & - & + \\
\hline MMBF 01/01 & - & + & - & - & + & - & - & + & - & - & + & - \\
\hline
\end{tabular}

${ }^{1}$ Média de oito repetições; ${ }^{2}$ Inócuo; ${ }^{3}$ Fungistase e ${ }^{4}$ Fungicida. Os símbolos de $+\mathrm{e}$ - indicam a ocorrência (+) ou não (-) dos efeitos da temperatura sobre o micélio dos isolados.

Tabela 3. Análise do efeito fungistático sobre a taxa de crescimento micelial dos isolados de Cylindrocladium spathiphylli causado pela temperatura de $33^{\circ} \mathrm{C}$, em cada período testado.

\begin{tabular}{|c|c|c|c|c|c|}
\hline \multirow{3}{*}{ ISOLADOS } & \multirow{3}{*}{ TRATAMENTOS } & \multicolumn{4}{|c|}{ PERÍODOS (DIAS) } \\
\hline & & 3 & 6 & 9 & 12 \\
\hline & & \multicolumn{4}{|c|}{ TAXA DE CRESCIMENTO DO MICÉLIO (MM/DIA) } \\
\hline \multirow{3}{*}{ LFEEI016 } & $23^{\circ} \mathrm{C}$ & $4,3^{1} a^{2}$ & - & - & - \\
\hline & $33-23^{\circ} \mathrm{C}$ & $3,1 \mathrm{~b}$ & - & - & - \\
\hline & Diferença ${ }^{3}$ & 1,2 & & & \\
\hline \multirow{3}{*}{ MMBF 01/01 } & $23^{\circ} \mathrm{C}$ & $6,0^{1} \mathrm{a}^{2} \mathrm{D}^{3}$ & 6,4 a C & 7,8 a $\mathrm{A}$ & 6,9 a B \\
\hline & $33-23^{\circ} \mathrm{C}$ & $5,1 \mathrm{~b} \mathrm{~B}^{3}$ & $5,1 \mathrm{~b} \mathrm{~B}$ & $6,0 \mathrm{~b} \mathrm{~A}$ & $5,9 \mathrm{~b} \mathrm{~A}$ \\
\hline & Diferença & 0,9 & 1,3 & 1,8 & 1,0 \\
\hline
\end{tabular}

${ }^{1}$ Média de oito repetições; ${ }^{2}$ Letras minúsculas iguais, na coluna, não diferem entre si ao nível de $5 \%$ de probabilidade, segundo o teste não-paramétrico de Mann-Whitney; ${ }^{3}$ Letras maiúsculas iguais, na linha, não diferem entre si ao nível de $5 \%$ de probabilidade, segundo o teste $\mathrm{T}$ da análise não-paramétrica de Kruskal-Wallis; ${ }^{3}$ Diferença $=\left[\left(23^{\circ} \mathrm{C}\right)-\left(33\right.\right.$ para $\left.\left.23^{\circ} \mathrm{C}\right)\right]$. 
sozinhos não exibiram qualquer efeito fungicida, enquanto a combinação quitosana a $2,5 \%$ e todos os extratos apresentaram mais efeito fungistático do que efeito fungicida. Mudanças na morfologia conidial do fungo foram observadas com quitosana a 1,5\%, após 7 horas de incubação.

Mudança na atmosfera - ou seja - aumentando-se a concentração de gás carbônico e diminuindo a de oxigênio pode provocar efetivo efeito fungistático sobre fungos em armazenamento de frutas (27).

Barrera-Necha et al. (3) testaram in vitro atividade antifúngica de óleos essenciais e seus compostos sobre o crescimento micelial de Fusarium oxysporum f. sp. gladioli. Eles observaram que todos os compostos de plantas testados, com exceção de cineole, tiveram efeito fungicida e fungistático sobre o micélio do fungo.

Krugner \& Bacchi (25) e Kuniega-Alonso et al. (26) reportaram que o crescimento micelial ou vegetativo é uma característica importante para a grande maioria dos fungos, sobretudo para os fitopatogênicos, sendo o micélio responsável pelo processo de colonização do substrato, absorção de nutrientes e sobrevivência saprofítica na forma de micélio em restos culturais, ou ainda formando as chamadas estruturas de resistência. Além disto, o micélio produz enzimas para facilitar a degradação do substrato em substâncias facilmente assimiláveis. Sendo assim, a alteração fungistática nos micélios dos isolados de C. spatiphylli pode ter causado alteração, também, no padrão das enzimas extracelulares estudadas.

Verificando então as enzimas extracelulares nos isolados alterados, constatou-se que na média geral das enzimas, a lacase apresentou a maior área, seguida da lipase, depois carboximetilcelulase (CMC) e, por último, a amilase, que não apresentou nenhuma área por nenhum isolado alterado pela fungistase. Na média de todas as enzimas entre os isolados, o isolado que apresentou a maior área das enzimas foi o MMBF 01/01 - três dias, depois o MMBF 01/01 - nove dias e, por último, o isolado LFEEI016 - três dias (Tabela 4).

Ainda analisando-se pela média geral, os isolados alterados apresentaram comportamento semelhante nas enzimas catalase e gelatinase em relação às demais enzimas, mas, tanto a catalase, quanto a gelatinase, apresentaram, semelhantemente, valor de intensidade igual por todos os isolados conjuntamente (Tabela 4).
Analisando-se por isolado, tanto o MMBF 01/01 - três dias, quanto o MMBF 01/01 - nove dias, apresentaram maior área da enzima lacase, depois a lipase e CMC e não houve área para a amilase. A gelatinase apresentou maior intensidade em comparação com a catalase, por ambos os isolados (Tabela 4).

Quanto ao isolado LFEEI016 - três dias, este exibiu, de modo estatisticamente semelhante, valor de grandeza de áreas das enzimas lacase, lipase, CMC e amilase em relação aos isolados MMBF 01/01 - três e nove dias, mas a enzima catalase apresentou neste isolado intensidade moderada e ausência para gelatinase (Tabela 4).

De acordo com os dados da Tabela 4, a diminuição das áreas de todas as enzimas foi proporcional em relação ao tempo de exposição do isolado MMBF $01 / 01$ à temperatura de $33^{\circ} \mathrm{C}$ e depois retorno para $23^{\circ} \mathrm{C}$.

Além da alteração na taxa de crescimento micelial dos isolados pela temperatura de $33^{\circ} \mathrm{C}$ (Tabela 3), as áreas das enzimas também foram alteradas, o que era esperado, principalmente, da lacase e carboximetilcelulase (CMC). O isolado MMBF 01/01 normal apresentou na média uma área de $1808,82 \mathrm{~mm}^{2}$ da enzima lacase e para CMC não se detectou área (Tabela 1). O isolado alterado MMBF 01/ 01 - três dias exibiu uma área média de $2256,0 \mathrm{~mm}^{2}$ de lacase e 328,4 $\mathrm{mm}^{2}$ para CMC (Tabela 4). O isolado LFEEI016 normal apresentou uma área média de $747,23 \mathrm{~mm}^{2}$ da lacase e $0,0 \mathrm{~mm}^{2}$ de CMC, enquanto que o isolado alterado LFEEI016 - três dias exibiu a lacase com uma área média de $1817,1 \mathrm{~mm}^{2}$ e 22,2 $\mathrm{mm}^{2}$ de CMC (Tabelas $1 \mathrm{e} \mathrm{4}$ ).

Essa alteração no micélio dos isolados do fungo e, consequentemente, nas áreas das enzimas faz sentido, pois o micélio é o responsável pela produção e liberação das enzimas, de acordo com Krugner \& Bacchi (25) e Kuniega-Alonso et al. (26). Além disto, a detecção de área de atividade de CMC nos isolados de C. spathiphylli alterados por fungistase faz agora corroborar os dados de Ruegger \& Tank-Tornisielo (38) que citaram a produção de CMC por C. clavatum.

Em função da maior área da enzima lacase em relação às áreas das demais enzimas nos isolados normais e alterados, pela diferença de área, tanto da lacase, quanto das demais, entre o isolado do Instituto Biológico e o da Epagri, salienta-se verificar a severidade da doença na planta entre os isolados e em condições naturais realizar estudos de cromatografia para averiguar a evolução da LC em comparação às

Tabela 4. Enzimas extracelulares detectadas em isolados de Cylindrocladium spathiphylli, de espatifilo, alterados por fungistase, em meios de cultura específicos mantidos em condições de incubação em estufa tipo BOD.

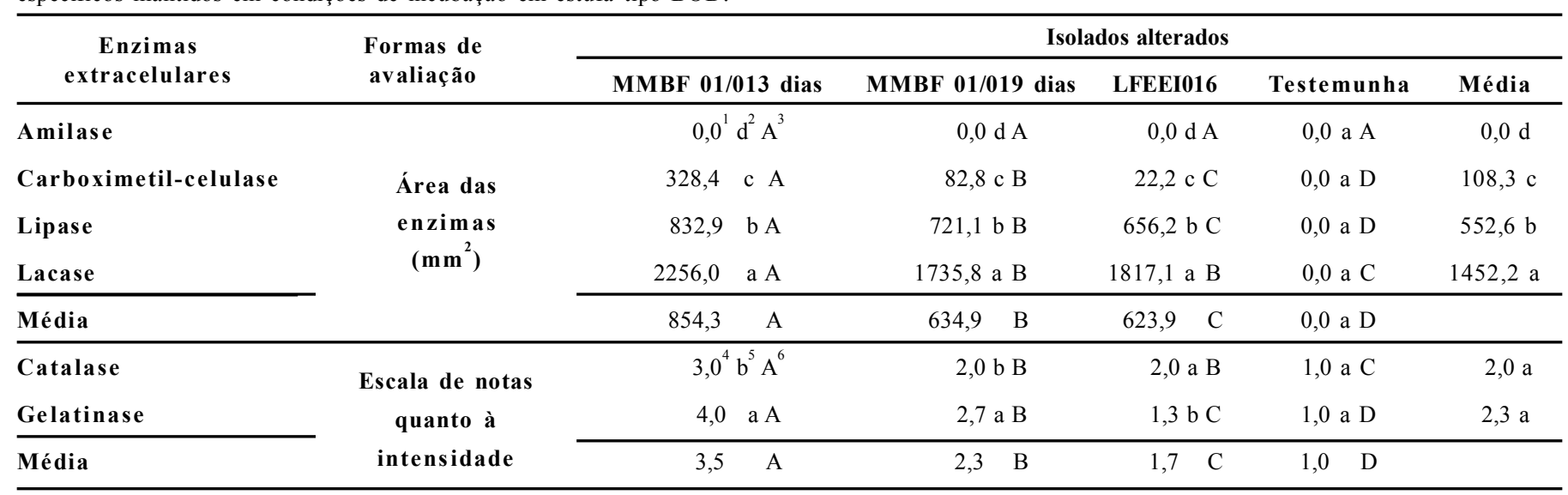

${ }^{1}$ Média de seis repetições; ${ }^{2}$ Letras minúsculas iguais, na coluna, para as enzimas amilase, carboximetilcelulase, lipase e lacase por isolado não diferem entre si ao nível de $1 \%$ de probabilidade, segundo teste $\mathrm{T}$ da análise não-paramétrica de Kruskal-Wallis; ${ }^{3}$ Letras maiúsculas iguais, na linha, entre os isolados por enzima não diferem entre si ao nível de $1 \%$ de probabilidade, segundo teste $\mathrm{T}$ da análise não-paramétrica de Kruskal-Wallis; ${ }^{4}$ Média de seis repetições. Escala de notas, sendo $1=$ ausência (ou - = símbolo: ausência); $2=$ fraca (ou $+=$ símbolo: fraca); $3=$ =moderada (ou ++ =símbolo: moderada); 4=intensa (ou +++=símbolo: intensa), sendo que para catalase refere-se ao tamanho da formação das bolhas e para a gelatinase quanto à liquefação ou não do meio; ${ }^{5}$ Letras minúsculas iguais, na coluna, para as enzimas catalase e gelatinase por isolado não diferem entre si ao nível de $1 \%$ de probabilidade, segundo teste da análise nãoparamétrica de Mann-Whitney; ${ }^{6}$ Letras maiúsculas iguais, na linha, entre os isolados por enzima não diferem entre si ao nível de $1 \%$ de probabilidade, segundo teste T da análise nãoparamétrica de Kruskal-Wallis. 
demais enzimas na patogênese do fungo na cultura.

\section{AGRADECIMENTOS}

Os autores agradecem a Dra. Christiane C. Aparecido, do Instituto Biológico/SP, e ao Dr. Alexandre Visconti, da Empresa de Pesquisa Agropecuária e Extensão Rural de Santa Catarina (EPAGRI / SC), pela disponibilização de isolados do fungo para a realização da pesquisa. Nosso agradecimento também ao Khalil M. Rodrigues, do Instituto Agronômico de Campinas, pela análise dos dados da Tabela 1, o que deu base para a realização das demais análises do presente trabalho.

\section{REFERÊNCIAS BIBLIOGRÁFICAS}

1. Agrios, G. N. Plant pathology. New York: Academic Press, 1988. $803 \mathrm{p}$.

2. Aparecido, C. C.; Furtado, E. L.; Figueiredo, M. B. Caracterização morfofisiológica de isolados do gênero Cylindrocladium. Summa Phytopathologica, Botucatu, v. 34, n. 1, p. 38-47, 2008.

3. Barrera-Necha, L. L.; Garduno-Pizana, C.; Garcia-Barrera, L. J. In vitro antifungal activity of essential oils and their compounds on mycelial growth of Fusarium oxysporum f. sp. gladioli (Massey) Snyder and Hansen. Plant Pathology Journal, Korea, v. 8, n. 1, p.17-21, 2009.

4. Basseto, M. A.; Bueno, C. J.; Chagas, H. A.; Rosa, D. D.; Padovani, C. R.; Furtado, E. L. Efeitos da simulação da solarização do solo com materiais vegetais sobre o crescimento micelial de fungos fitopatogênicos habitantes do solo. Summa Phytopathologica, Botucatu, v. 37, n. 3, p. 116-120, 2011.

5. Bastos, C. N. Produção de enzimas extracelulares por Crinipellis perniciosa. Fitopatologia Brasileira, Brasília, v. 30, p. $286-$ $288,2005$.

6. Bateman, D. F.; Bashan, H. G. Degradation of plant-cell walls and membranes by microbial enzymes. Physiological and Molecular Plant Pathology, London, v. 4, p. 316-355, 1976.

7. Bautista-Baños, S.; Hernández-López, M.; Bosquez-Molina, E.; Wilson, C.L. Effects of chitosan and plant extracts on growth of Colletotrichum gloeosporioides, anthracnose levels and quality of papaya fruit. Crop Protection, Guildford, v. 22, n. 9, p. 1087-1092, 2003.

8. Bourbonnais, R.; Paice, M. G. Oxidation of nonphenolic substrates-an expanded role for laccase in lignin biodegradation. FEBS Letters, Amsterdam, v. 267, p. 99-102, 1990.

9. Carvalho, P. O.; Campos, P. R. B.; Noffs, M. A.; Oliveira, J. G.; Shimuzu, M. T.; Silva, D. M. Aplicação de lipases microbianas na obtenção de concentrados de ácidos graxos poliinsaturados. Química Nova, São Paulo, v. 26, n. 1, p. 75-80, 2003.

10. Chase, A. R.; Poole, R. T. Effects of potting medium $\mathrm{pH}$ and air temperature on severity of Cylindrocladium root and petiole rot of Spathiphyllum sp. Plant Disease, St. Paul, v. 71, p. 509-511, 1987.

11. Claus, H. Laccases and their occurrence in prokaryotes. Archives of Microbiology, Berlin, v. 179, p. 145-150, 2003.

12. Clutterbuck, A. J. Absence of laccase from yellow-spored mutants of Aspergillus nidulans. Journal of General Microbiology, London, v. 70, p. 423-435, 1972.

13. Conceição, D. M.; De Angelis, D. A.; Bidoia, E. D.; De Angelis, D. F. Fungos isolados do Rio Atibaia - SP e Refinaria de Petróleo biodegradadores de compostos fenólicos. Arquivos do Instituto Biológico, São Paulo, v. 72, n. 1, p. 99-106, 2005.

14. Coutinho, L. N.; Aparecido, C. C. Podridão de colo de plantas de lírio da paz (Spathiphyllum wallisii) causadas por fungo do gênero Cylindrocladium. Fitopatologia Brasileira, Brasília, v. 26, p. 427, 2001. Resumo.

15. Cuzzi, C.; Link, S.; Vilani, A.; Onofre, S. B. Enzimas extracelulares produzidas por fungos endofíticos isolados de Baccharis dracuncufolia D.C. (Asteraeceae). Global Science and Technology, Rio Verde, v. 4, n. 2, p. 47-57, 2011.
16. Dianese, J. C. Patologia vegetal: agressão e defesa em sistemas planta-patógeno. Brasília: Ed. UnB, 1990. 139 p.

17. Dixon, R. A.; Harrison, M. J.; Lamb, C. J. Early events in the activation of plant defense responses. Annual Review of Phytopathology, Palo Alto, v. 32, p. 479-501, 1994.

18. Geiger, J. P.; Nicole, M.; Nandris, D.; Rio, B. Root-rot diseases of Hevea brasiliensis.1. Physiological and biochemical aspects of host aggression. European Journal of Forest Pathology, Hamburg, v. 16, p. 22-37, 1986.

19. Gieck, K. Manual de formulas técnicas. São Paulo: Hemus, s.d. 29 p.

20. Gowariker, V.; Krishnamurthy, V. N.; Gowariker, S.; Dhanorkar, M.; Paranjape, K. The fertilizer encyclopedia. New York: John Wiley, 2009. $872 \mathrm{p}$.

21. Griffin, D. H. Fungal physiology. 2nd ed. New York: John Wiley, 1994. $457 \mathrm{p}$.

22. Grijalba, P. E.; Palmucci, H. E. Cylindrocladium spathiphylli, a causal agent of root and crown rot of Spathiphyllum wallisii in Buenos Aires, Argentina. Phyton, Buenos Aires, v. 76, p. 79-84, 2007.

23. Kasana, R. C.; Salwan, R.; Dhar, H.; Dutt, S.; Gulati, A. A rapid and easy method for the detection of microbial cellulases on agar plates using gram's iodine. Current Microbiology, New York, v. 57, p. 503-507, 2008.

24. Kolattukudy, P. E. Enzymatic penetration of the plant cuticule by fungal pathogens. Annual Review of Phytopathology, v. 23, p. 223- 250, 1985.

25. Krugner, T. L.; Bacchi, L. M. A. Fungos. In: Bergamin Filho, A.; Kimati, H.; Amorin, L. (Ed.) Manual de fitopatologia. São Paulo: Agronômica Ceres, 1995. p. 46-95.

26. Kuniega-Alonso, S.; Alfenas, A. C.; Maffia, L. A. Sobrevivência de micélio e escleródios de Rhizoctonia solani tratados com Trichoderma spp., em restos de cultura de Eucalyptus sp. Fitopatologia Brasileira, Brasília, v. 30, n. 2, p. 164-168, 2005.

27. Littlefield, N. A.; Wankier, B. N.; Salunkhe, D. K.; Mcgill, J. N. Fungistatic effects of controlled atmospheres. Applied and Environmental Microbiology, Washington, v. 14, n. 4, p. 579$581,1966$.

28. Mishra, R. R.; Pandey, K. K. Studies on soil fungistasis: effect of certain physical and biological factores. Plant and Soil, The Hague, v. 49, p. 355-366, 1978.

29. Nwufo, M. I.; Fajola, A. O. Production of amylolytic enzymes in culture by Botryodiplodia theobromae and Sclerotium rolfsii associated with the corn rots of Colocasia esculenta. Acta Microbiologica Hungarica, Budapest, v. 35, p. 371-378, 1988.

30. Oliveira, D. T. M. Lipase extracellular de fungo filamentoso: isolamento e caracterização parciais. 2000. 152 f. Dissertação (Mestrado em Ciências de Alimentos) - Faculdade de Farmácia da UFMG, Belo Horizonte, 2000

31. Oliveira Silva, R. L.; Luz, J. S.; Silveira, E. B.; Cavalcante, U. M. T. Fungos endofíticos em Annona spp.: isolamento, caracterização enzimática e promoção do crescimento em mudas de pinha (Anonna squamosa L.). Acta Botânica Brasilica, São Paulo, v. 20, n. 3, p. 649-655, 2006.

32. Parodi, L. R.; Dimitri, M. J. Enciclopedia argentina de agricultura y jardinería. Bueno Aires: Ed. ACME, 1978. 1161 p.

33. Pascholati, S. F. Fitopatógenos: arsenal enzimático. In: Bergamin Filho, A.; Kimati, H.; Amorim, L. (Ed.). Manual de fitopatologia. 3.ed. São Paulo. Agronômica Ceres, 1995. p. 343-364. v.1: Princípios e conceitos.

34. Pereira, W. V. Caracterização e identificação molecular de espécies de Colletotrichum associadas à antracnose da goiaba no Estado de São Paulo. 2009. 79 f. Dissertação (Mestrado em Ciências) - Universidade do Estado de Paulo, Piracicaba.

35. Reed, G. Enzymes in food processing. 2. ed. Wisconsin: Academic Press, 1975. 573 p.

36. Reinhammar, B.; Malstrom, B. G. Blue copper-containing oxidases. In: Lontie, L. (Ed.) Copper proteins and copper enzymes. Boca Raton: CRC, 1981. p 1-35.

37. Reis, A.; Mafia, R. G.; Silva, P. P.; Lopes, C. A.; Alfenas, A. C. Cylindrocladium spathiphylli, causal agent of Spathiphyllum root 
and collar rot in the Federal District - Brazil. Fitopatologia Brasileira, Brasília, v. 29, n. 1, p. 102, 2004.

38. Ruegger, M. J. S.; Tauk-Tornisielo, S. M. Atividade da celulase de fungos isolados do solo da Estação Ecológica de Juréia-Itatins, São Paulo, Brasil. Revista Brasileira de Botânica, São Paulo, v. 27, n. 2, p. 205-211, 2004.

39. Shin, K-Soo; Kim, C-Jin. Decolorisation of artificial dyes by peroxidase from the white-rot fungus, Pleurotus ostreatus. Biotechnology Letters, Dordrecht, v. 20, p. 569-572, 1998.

40. Singh, R.; Saxena, V. C. Pectinolytic, cellulolytic, amylase ad protease production by three isolates of Fusarium solani variable in their virulence. Indian Journal of Mycology and Plant Pathology, Udaipur, v. 19, p. 22-29, 1989.

41. Termorshuizen, A. J.; Van Rijn, E.; Van Der Gaag, D. J.; Alabouvette, C.; Chen, Y.; Lagerlof, J.; Malandrakis, A. A.; Paplomatas,
E. J.; Ramert, B.; Ryckeboer, J.; Steinberg, C.; Zmora-Nahum, S. Suppressiveness of 18 composts against 7 pathosystems: variability in pathogen response. Soil Biology \& Biochemistry, Amsterdan, v. 38, p. 2461-2477, 2006.

42. Tortora, G. J.; Funke, B. R.; Case, C. L. Microbiologia. 10. ed. Porto Alegre: Artmed, 2012. 964 p.

43. Trigiano, R. N.; Windham, M. T.; Windham, A. S. Fitopatologia: conceitos e exercícios de laboratório. 2. ed. Porto Alegre: Artmed, 2010. 576 p.

44. Vermelho, A. B.; Pereira, A. F.; Coelho, R. R. R.; Souto-Padrón, T. Práticas de microbiologia. Rio de Janeiro: Guanabara Koogan, 2006. 239 p.

45. Visconti, A.; Bettiol, W.; Morandi, M. A. B. Efeito de hidrolisado de peixe sobre o crescimento micelial e controle de Cylindrocladium spathiphylli em espatifilo. Summa Phytopathologica, Botucatu, v.36, n.4, p.298-308, 2010 . 